archives

of thermodynamics

Vol. 36(2015), No. 1, 111-123

DOI: $10.1515 /$ aoter-2015-0008

\title{
Influence of the type of working fluid in the lower cycle and superheated steam parameters in the upper cycle on effectiveness of operation of binary power plant
}

\section{ALEKSANDER A. STACHEL ${ }^{1}$ SEAWOMIR WIŚNIEWSKI}

West-Pomeranian University of Technology, Department of Heat Engineering, Piastów 17, 70-310 Szczecin, Poland

\begin{abstract}
In the paper presented have been the results of the analysis of effectiveness of operation of binary power plant consisting of combined two Clausius-Rankine cycles, namely the binary cycle with water as a working fluid in the upper cycle and organic substance as a working fluid in the lower cycle, as well as a single fluid component power plant operating also in line with the C-R cycle for superheated steam, with water as a working fluid. The influence of the parameters of superheated steam in the upper cycle has been assessed as well as the type of working fluid in the lower cycle. The results of calculations have been referred to the single-cycle classical steam power plant operating at the same parameters of superheated steam and the same mass flow rate of water circulating in both cycles. On the basis of accomplished analysis it has been shown that the binary power plant shows a greater power with respect to the reference power plant.
\end{abstract}

Keywords: Binary power plant; ORC power plant

\section{Nomenclature}

$$
\begin{array}{ll}
h & - \text { specific enthalpy, } \mathrm{kJ} / \mathrm{kg} \\
\dot{m} & - \text { mass flowrate, } \mathrm{kg} / \mathrm{s} \\
N & - \text { power, } \mathrm{kW}
\end{array}
$$

\footnotetext{
${ }^{1}$ Corresponding Autor: E-mail: andrzej.stachel@zut.edu.pl
} 


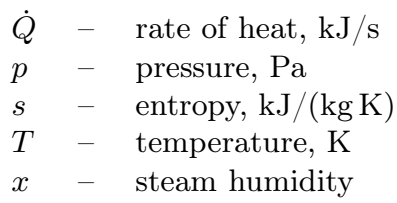

\section{Greek symbols}

$\eta \quad-$ efficiency

\section{Subscripts}

$\begin{array}{lll}\text { cond } & - & \text { condensation heat } \\ \text { CR } & - & \text { Clausius-Rankine cycle } \\ \text { evap } & - & \text { evaporation heat } \\ n & - & \text { low-boiling point fluid } \\ o & - & \text { organic working fluid } \\ \text { rem } & - & \text { removed heat } \\ \text { s } & - & \text { water/steam } \\ \text { sup } & - & \text { supplied heat } \\ 1,2 s, 3, \ldots & - & \text { characteristic points of the cycle }\end{array}$

\section{Superscripts}

$$
\begin{array}{lll}
R & - & \text { reference cycle } \\
U & - & \text { upper cycle } \\
L & - & \text { lower cycle } \\
B & - & \text { binary cycle }
\end{array}
$$

\section{Introduction}

The growing energy needs and environmental concerns induce the search for new sources of energy and new, more efficient energy conversion systems. A trend in the energy sector are also the activities aimed at development of medium- and low-temperature energy conversion systems, including waste energy systems. In the conventional systems, the possibility of using energy with low-temperature parameters are limited only for heating purposes. In order to use such energy fluxes for electric energy production the appropriate systems with Organic-Rankine cycle (ORC) with organic working fluid should be developed. Work analysis of ORC systems is the subject of many papers. These analyses concern many aspects, including: the selection of suitable evaporation temperature, type of working fluid $[1,2]$ or ORC systems connectivity with other energy systems $[3,4]$.

In this paper a binary power plant (with two working fluids) has been analyzed, consisting of two cycles: upper and bottom cycle, in which water and low-boiling organic substance are used as working fluids, respectively. 
The scheme of described power plant is shown in Fig. 1. The plant consists of two cycles, namely the upper and lower ones, where water and organic substance respectively are the working fluids. The cycles of binary power plant are coupled by a common heat exchanger of the condenser-evaporator type, where heat of condensation of water in the upper cycle is transferred to the cycle featuring the organic fluid to carry out its evaporation.

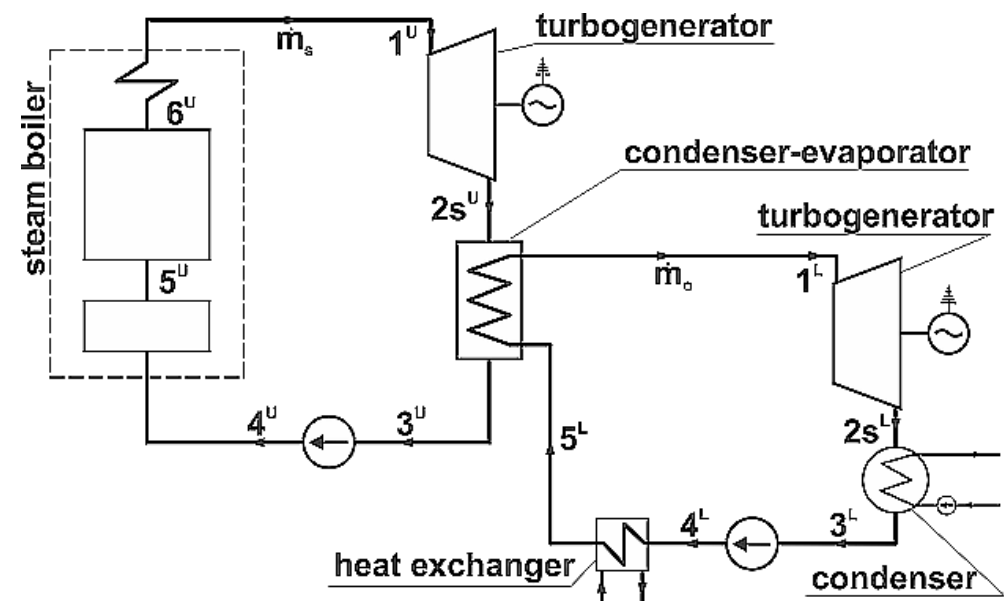

Figure 1: Schematic of installation of a binary plant.

The upper cycle of binary power plant, encompasses the steam boiler, superheater, turbine driving the generator, heat exchanger of condenserevaporator type and circulation pump. The water cycle is supplied with heat from external heat source (boiler), which serves for heating of water and its evaporation as well as production of superheated steam in the superheater. The fluid in the upper cycle, following the expansion process in the turbine, is directed to the heat exchanger of condenser-evaporator type where condensation of steam takes place and subsequently transfer of heat to the fluid in the lower cycle occurs to permit its evaporation. The condensate is directed to the steam boiler by means of the circulation pump.

The lower cycle encompasses: the heat exchanger of condenser-evaporator type, turbine driving the generator, condenser, circulation pump, additional heat exchanger. The organic fluid circulating in that cycle is heated from temperature of condensation to temperature of evaporation and subsequently is directed to the evaporator. From there saturated steam is directed to the turbine, where isentropic expansion to the pressure present in condenser takes place. Such steam, following the cooling process to the 
saturation temperature, undergoes condensation and by means of the circulation pump is directed to heaters, where it is heated to evaporation temperature. Heating of condensate can be realized partially from the low temperature energy resource.

In both cases the Clausius-Rankine cycle is realized with only that difference that in the upper cycle it is with superheated steam whereas in the lower cycle with the saturated steam [5]. Schematics of the above cycles together with constituent thermodynamical processes for the primary cycle and the upper and lower cycles of the binary power plant, have been presented in Fig. 2.
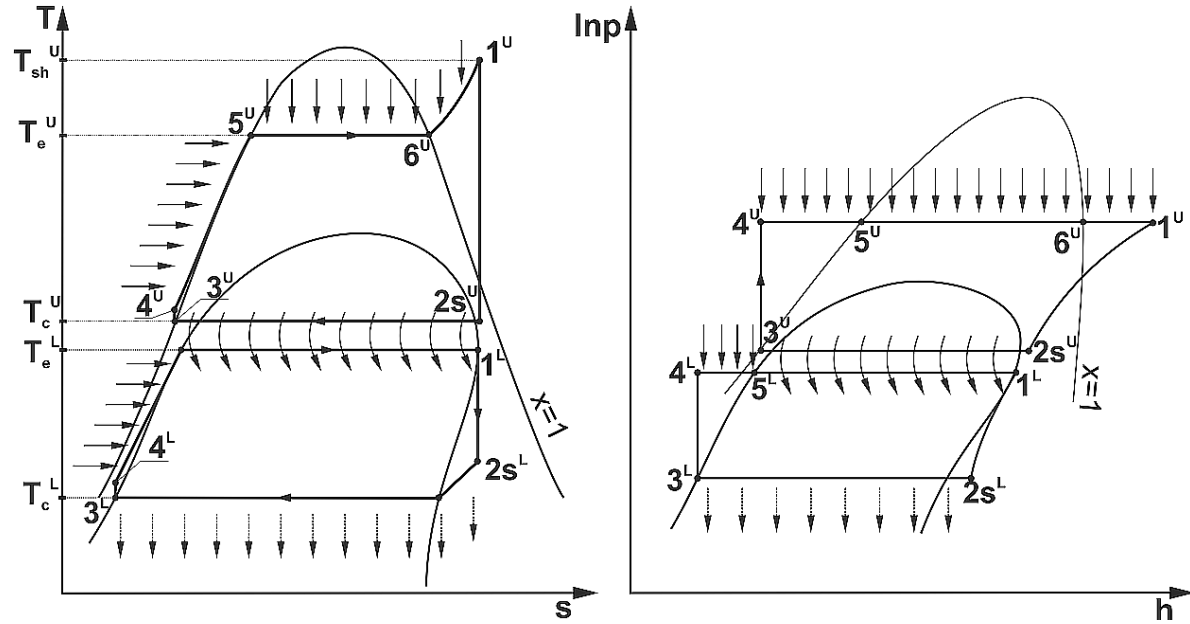

Figure 2: Cycle of thermodynamics processes of fluids in the upper and lower cycle of binary power plant.

Each of the considered installations consists of two isobars (supply and removal of heat) and two isentropes (expansion and compression). Heat is supplied to the circulation fluid in order to heat it to saturation conditions, evaporate and superheat during the isobaric process (4-1). Obtained steam is directed to the turbine blades, where it undergoes expansion from pressure $p_{1}$ to pressure $p_{2}(1-2 \mathrm{~s})$, as a result of which kinetic energy of steam is converted to mechanical work. Turbine drives the generator producing in such way the electricity.

In the case of upper cycle of the binary power plant the heat is removed in the condenser $\left(2 \mathrm{~s}^{\mathrm{U}}-3^{\mathrm{U}}\right)$ and transferred to the working fluid of the lower cycle in order to evaporate it $\left(5 \mathrm{~d}^{\mathrm{L}}-1 \mathrm{~d}^{\mathrm{L}}\right)$. In the case of the lower cycle, vapour expanded in the turbine is directed to the condenser, where in the 
course of isobaric process it gives away heat to water cooling the condenser $\left(2 \mathrm{~s}^{\mathrm{L}}-3^{\mathrm{L}}\right)$, which subsequently removes heat to the surroundings. The condensate formed in the condenser is pumped through the circulation pump $\left(3^{\mathrm{L}}-4^{\mathrm{L}}\right)$ to the boiler, where it again undergoes the evaporation process.

A binary power plant has been compared against a classical steam power plant (single component) with superheated steam, where water was a working fluid and its flow rate and supearheating temperature was specified (Fig. 3). The power plant operates according to the C-R cycle and is further named the reference cycle. The comparison has been carried out at the assumption that both power plants operate at the same conditions of isobaric heat supply from the upper heat source (heating, evaporation and superheating) and same condensation temperature of circulation fluid during the process of heat removal to the lower heat source.
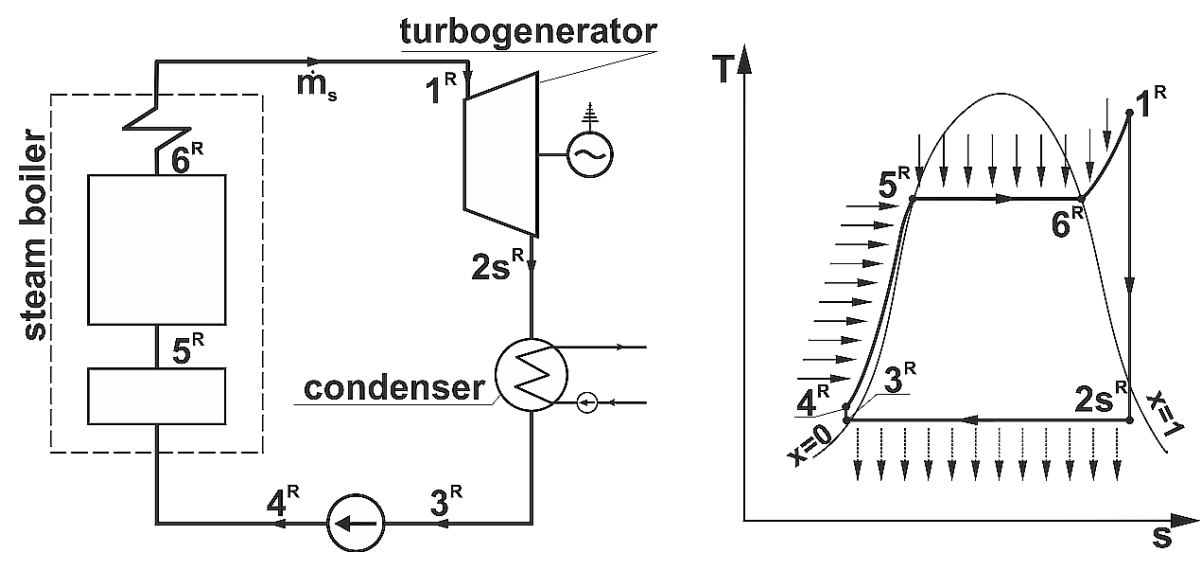

Figure 3: Schematic of the reference power plant with superheated steam and cycle of thermodynamics processes of water.

\section{Methodology of calculations}

For the sake of possibility of theoretical assessment of the effectiveness of operation of different variants of power stations there ought to be determined all quantities characterizing the C-R cycle, namely the rate of supplied heat, rate of removed heat, obtained power and efficiency. The relations enabling determination of quantities characterizing the particular C-R cycles, according to which the installations run, have been presented below. 


\section{$2.1 \quad$ Binary power plant}

Rate of heat supplied for heating of organic fluid as well as for heating, evaporation and superheating of water in the upper cycle:

$$
\dot{Q}_{\text {sup }}^{B}=\dot{m}_{o}\left(h_{5}^{L}-h_{4}^{L}\right)+\dot{m}_{s}\left(h_{1}^{U}-h_{4}^{U}\right) .
$$

Rate of heat removed to surroundings from the lower cycle in the condenser:

$$
\dot{Q}_{r e m}^{B}=\dot{Q}_{r e m}^{L}=\dot{m}_{o}\left(h_{2 s}^{L}-h_{3}^{L}\right) .
$$

Binary cycle power as a sum of the powers of lower and upper cycles:

$$
N_{C R}^{B}=N_{C R}^{L}+N_{C R}^{U}=\dot{m}_{o}\left(h_{1}^{L}-h_{2 s}^{L}\right)+\dot{m}_{s}\left(h_{1}^{U}-h_{2 s}^{U}\right) .
$$

Efficiency of binary cycle of power plant:

$$
\eta_{C R}^{B}=\frac{N_{C R}^{L}+N_{C R}^{U}}{\dot{Q}_{\text {sup }}^{B}}=\frac{\dot{m}_{o}\left(h_{1}^{L}-h_{2 s}^{L}\right)+\dot{m}_{s}\left(h_{1}^{U}-h_{2 s}^{U}\right)}{\dot{m}_{o}\left(h_{5}^{L}-h_{4}^{L}\right)+\dot{m}_{s}\left(h_{5}^{U}-h_{4}^{U}\right)} .
$$

\subsection{Upper cycle of binary power plant}

Rate of supplied heat:

$$
\dot{Q}_{\text {sup }}^{U}=\dot{m}_{s}\left(h_{1}^{U}-h_{4}^{U}\right) .
$$

Rate of heat removed in condenser-evaporator to the organic fluid:

$$
\dot{Q}_{r e m}^{U}=\dot{m}_{s}\left(h_{2 s}^{U}-h_{3}^{U}\right) \text {. }
$$

Power of the Clausius-Rankine cycle:

$$
N_{C R}^{U}=\dot{m}_{s}\left(h_{1}^{U}-h_{2 s}^{U}\right) .
$$

Efficiency of the Clausius-Rankine cycle:

$$
\eta_{C R}^{U} \cong \frac{N_{C R}^{U}}{\dot{Q}_{\text {sup }}^{U}}=\frac{\left(h_{1}^{U}-h_{2 s}^{U}\right)}{\left(h_{1}^{U}-h_{4}^{U}\right)} .
$$




\subsection{Lower cycle of binary power plant}

Mass flow rate of low-boiling point fluid has been determined from the energy balance equation in the evaporator-condenser at the assumption that the rate of heat of condensation in the heat exchanger is equal to the rate of heat of evaporation:

$$
\dot{Q}_{\text {cond }}^{U}=Q_{\text {evap }}^{L}=\dot{m}_{s}\left(h_{2 s}^{U}-h_{3}^{U}\right)=\dot{m}_{o}\left(h_{1}^{L}-h_{5}^{L}\right) .
$$

Hence the mass flow rate of heated fluid:

$$
\dot{m}_{o}=\dot{m}_{s} \frac{\left(h_{2 s}^{U}-h_{3}^{U}\right)}{h_{1}^{L}-h_{5}^{L}} .
$$

Rate of supplied heat is equal to:

$$
Q_{\text {sup }}^{L}=\dot{m}_{o}\left(h_{1}^{L}-h_{4}^{L}\right) .
$$

Rate of heat removed from the condenser to surroundings:

$$
Q_{r e m}^{L}=\dot{m}_{o}\left(h_{2 s}^{L}-h_{3}^{L}\right) .
$$

Power of the Clausius-Rankine cycle:

$$
N_{C R}^{L}=\dot{m}_{o}\left(h_{1}^{L}-h_{2 s}^{L}\right) .
$$

Efficiency of the Clausius-Rankine cycle:

$$
\eta_{C R}^{L} \cong \frac{N_{C R}^{L}}{\dot{Q}_{\text {sup }}^{L}}=\frac{\left(h_{1}^{L}-h_{2 s}^{L}\right)}{\left(h_{1}^{L}-h_{4}^{L}\right)} .
$$

\subsection{Reference cycle of single component power plant}

The rate of heat supplied to the circulation water encompassing the processes of heating, evaporation and superheating of circulation fluid is:

$$
\dot{Q}_{\text {sup }}^{R}=\dot{m}_{s}\left(h_{1}^{R}-h_{4}^{R}\right) .
$$

Rate of heat removed in the condenser of reference cycle yields:

$$
\dot{Q}_{r e m}^{R}=\dot{m}_{s}\left(h_{2 s}^{R}-h_{3}^{R}\right) .
$$

The power of Clausius-Rankine cycle can be determined from the energy balance equation

$$
N_{C R}^{R}=\dot{Q}_{\text {sup }}^{R}-\dot{Q}_{r e m}^{R}
$$


or assuming that compression power is negligible with respect to expansion power it yields

$$
N_{C R}^{R}=N_{e x p}^{R}=\dot{m}_{s}\left(h_{1}^{R}-h_{2 s}^{R}\right) .
$$

In relation to the above assumption the Clausius-Rankine cycle efficiency in the case of reference cycle is determined from the relation

$$
\eta_{C R}^{R} \cong \frac{N_{C R}^{R}}{\dot{Q}_{\text {sup }}^{R}}=\frac{\left(h_{1}^{R}-h_{2 s}^{R}\right)}{\left(h_{1}^{R}-h_{4}^{R}\right)} .
$$

Values of particular thermal and calorific parameters of state in characteristic points of C-R cycle have been determined using the code REFPROP 7.0 [6], where particular values of enthalpies and entropy have been determined in the following way: enthalpy $h_{1}$ in location 1 has been determined on the basis of evaporation pressure and superheated steam temperature. On the basis of assumed parameters in the condenser (cooling water) condensation temperature has been determined and on such basis the condensation pressure in dependence to the kind of fluid. Enthalpy and entropy in location $2 \mathrm{~s}$ can be determined on the basis of isentropic expansion $\left(s_{1}=s_{2 s}\right)$ and condensation pressure. On the other hand enthalpy in location 3 , which is equal to the one in location $4,\left(h_{3}=h_{4}\right)$ can be determined for the condensation pressure and quality $x=0$.

\section{Results of calculations}

The influence of the working fluid used in the lower cycle and the parameters of superheated steam in the upper cycle on the effectiveness of operation of the binary plant has been considered on the basis of analytically determined efficiencies and powers of respective cycles, which have been compared to each other. Calculations encompassed different variants of operation of the binary power plant and its constituent cycles (upper and lower) as well as the reference power plant, which resulted from the assumed parameters of installation operation.

Calculations have been carried out for a unit mass flow rate of water (steam) in the upper cycle and the reference power plant $\left(\dot{m}_{p}=1 \mathrm{~kg} / \mathrm{s}\right)$, at the assumed temperature of steam superheating ranging from 623 to $663 \mathrm{~K}$ and water evaporation temperature ranging from 513 to $613 \mathrm{~K}$. Temperature of condensation of steam in the upper cycle has been assumed in the range from 368 to $398 \mathrm{~K}$, whereas condensation temperature in the lower 
cycle and the reference power plant was set as $303 \mathrm{~K}$. It has been assumed that the temperature difference in the condenser-evaporator heat exchanger was $T=3 \mathrm{~K}$. Investigations have been carried out for selected organic working fluids from the so called dry group of working fluids [7].

On the basis of detailed calculations the set of results has been obtained enabling the analysis of the efficiency and power of the power plant in function of the working fluid type as well as the parameters of superheated steam. Some of these relations are presented in the graphical form in Figs. 4-7. In Figs. 4 and 5 presented have been the relations between binary power plant power in function of evaporation temperature and superheated steam temperature respectively. The results of calculations have been referred to the selected (different) working fluids working in the lower cycle at the assumed condensation temperature in the condenser-evaporator heat exchanger $T_{\text {cond }}=373 \mathrm{~K}$ (for steam in upper cycle).

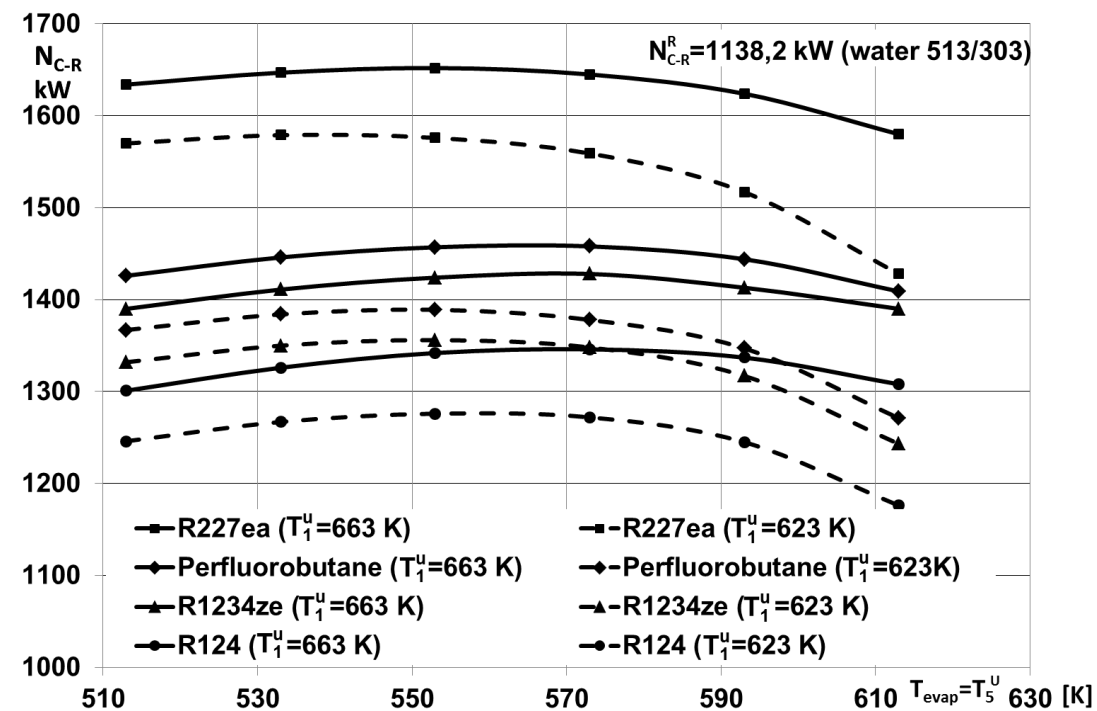

Figure 4: Influence of superheated steam temperature $\left(T_{1}\right)$ in the upper cycle on the power of binary power plant for different working fluids in the lower cycle $\left(T_{\text {cond }}=373 \mathrm{~K}\right)$.

The influence of the parameters of superheated steam and evaporation on the power of binary power plant at the assumed condensation temperature in the condenser-evaporator heat exchanger $\left(T_{\text {cond }}=393 \mathrm{~K}\right)$ has been presented on the example of the working fluid R124 (Fig. 6), used in the lower cycle. 


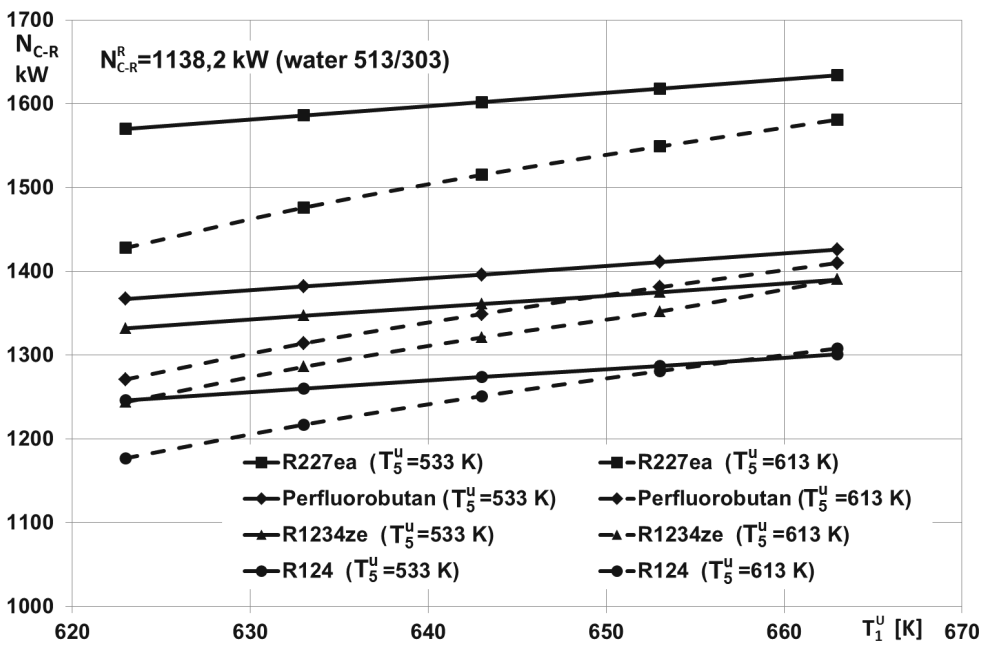

Figure 5: Influence of the water evaporation temperature $\left(T_{5}\right)$ on the power of binary power plant for different working fluids in the lower cycle $\left(T_{\text {cond }}=373 \mathrm{~K}\right)$.

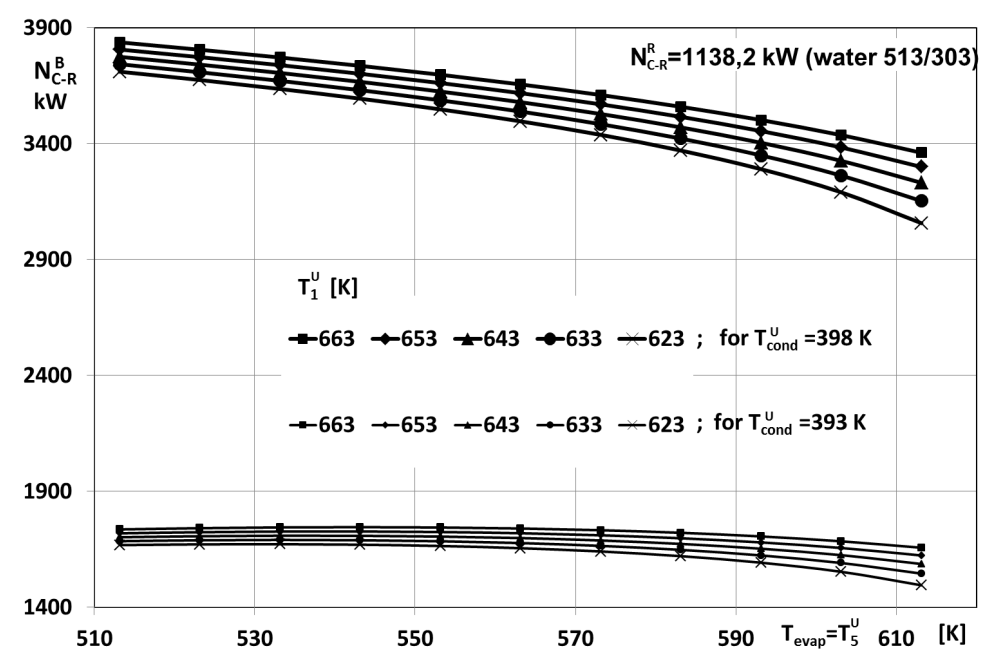

Figure 6: Influence of water evaporation temperature and superheated steam temperature on the binary plant power for R124 as working fluid in the lower cycle $\left(T_{\text {cond }}=393 \mathrm{~K}\right.$ and $\left.398 \mathrm{~K}\right)$.

In Fig. 7 presented has been the maximum power of the binary power plant as well as the values of power obtained in the upper cycle (steam) and the lower cycle (organic fluid) possible to be attained at adequate selection 
of working fluids and the parameters of operation of the installation. In figure presented has been also the efficiency of the binary power plant for these configurations.

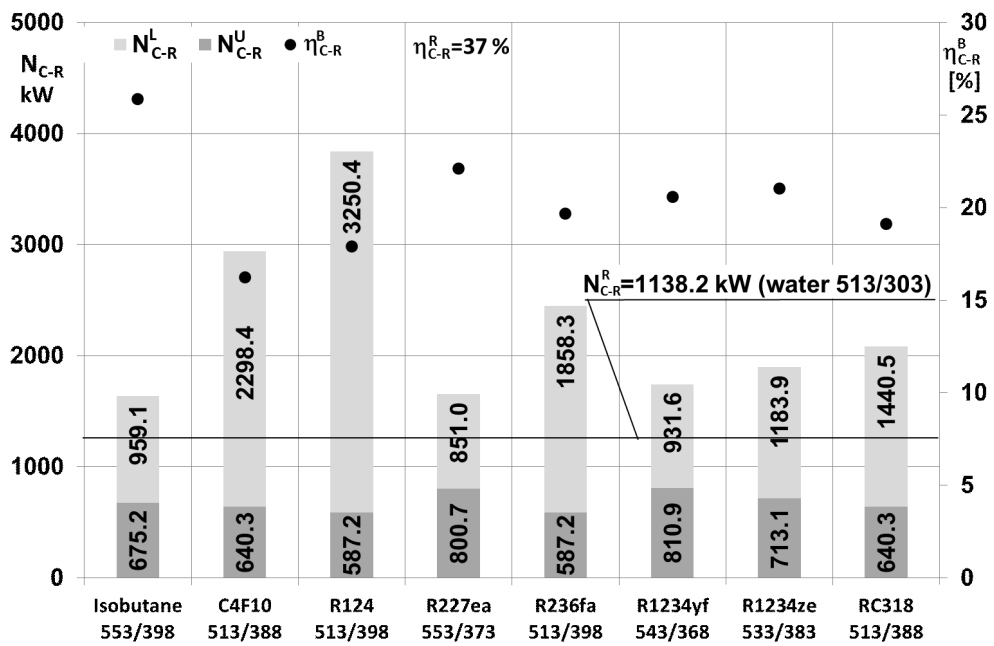

Figure 7: Maximum power of binary power plant for different working fluids in the lower cycle obtained at specified evaporation and condensation temperatures $\left(T_{\text {evap }} / T_{\text {cond }}\right)$ of steam in the upper cycle (temperature of superheated steam $\left.T_{1}=663 \mathrm{~K}\right)$.

In the figures presented are also values of powers possible to be obtained in the reference power plant operating at the superheating temperature of 663 $\mathrm{K}$ and condensation temperature of $303 \mathrm{~K}$.

\section{Conclusions}

A detailed analysis of the results of calculations enables to conclude that the effectiveness of operation of the binary power plant depends both on the type of working fluid used in the lower cycle as well as the parameters of steam in the upper cycle (superheating temperature, evaporation temperature or equivalent evaporation temperature) [8-10].

Increase of the superheating temperature renders the increase of the power and efficiency of installation of binary plant. On the other hand the increase of evaporation temperature (evaporation pressure) does not unanimously convert to the increase of the installation efficiency. Presented in Fig. 6 sample distribution of the binary cycle power with R124 as working 
fluid used in the lower cycle, constructed for the steam condensation temperature in the condenser-evaporator heat exchanger equal to $T_{\text {cond }}=393 \mathrm{~K}$ (and $398 \mathrm{~K}$ ), indicates that the maximum power of the plant is related to the specified water evaporation temperature in the upper cycle.

An important quantity which must be taken into account in the assessment of operation of the binary power plant is also condensation/evaporation temperature in the condenser/evaporator heat exchanger, which combines the upper and lower cycles. It stems from the accomplished analyses that the increase of condensation temperature directly influences the increase of power and efficiency of the binary power plant. Therefore during selection of the optimal variant of binary plant operation, apart from selection of the working fluid, there ought to be specified appropriate evaporation (condensation) temperatures so to obtain the maximum power at the account of the simultaneous influence of the working fluid.

Analysis of the results of calculations enables to conclude that the power of binary power plant surpasses, and in some cases significantly, the power of the single-cycle steam reference power plant, operating at the same parameters of the heat supply and removal. That results from the obtained power of the low-temperature (lower) cycle which causes the significant increase of the summative power of the binary plant. At the same time the binary power plant, in comparison with the reference one, features a smaller efficiency than the analogous reference power plant.

Received 10 December 2014

\section{References}

[1] Mikielewicz D., Mikielewicz J.: Optimal boiling temperature for ORC installation. Arch. Thermodyn. 33(2012), 3, 27-37.

[2] Nowak W., Borsukiewicz-Gozdur A., Wiśniewski, S.: Influence of working fluid evaporation temperature in the near-critical point region on the effectiveness of ORC power plant operation. Arch. Thermodyn. 33(2012), 3, 77-87.

[3] ZióŁkowski P., Mikielewicz D., Mikielewicz J.: Increase of power and efficiency of the $900 \mathrm{MW}$ supercritical power plant through incorporation of the ORC. Arch. Thermodyn. 34(2013), 4, 51-71.

[4] Wiśniewski S., Borsukiewicz-Gozdur A.: The influence of vapor superheating on the level of heat regeneration in a subcritical ORC coupled with gas power plant. Arch. Thermodyn. 31(2010), 3, 185-199.

[5] Chmielniak T.: Power generation technologies. Publishers of Silesian University of Technology, Gliwice 2004. 
[6] National Institute of Standards and Technology, 2002. Standard Reference Database 23, Reference Fluid Thermodynamic and Transport Properties - Refprop 7.0, US.

[7] Badr O., Probert S.D., O'Callaghan W.P.: Selecting a working fluid for a Rankine-cycle engine Appl. Energ. 21(1985), 1-42.

[8] CAŁY P.: Assessment of the influence of evaporation temperature and superheated steam temperature as well as waste heat temperature of the heat source on the effectiveness of operation of binary plant. MSc thesis, west-Pomierian University of Technology, Szczecin 2012.

[9] Nowak W., Stachel A.A., Borsukiewicz-Gozdur A.: Assessment of the influence of evaporation temperature on effectiveness of operation of binary power plant with superheated steam. In: Proc. 10th Int. Symposium: Heat Transfer and Renewable Sources of Energy, HTRSE 2006. Szczecin 2006.

[10] Stachel A.A. et al.: Analysis and evaluation of the possibility of utilisation of new ways of efficiency increase of operation of the power plant and heat and power plant suppllied with geothermal water of medium enthalpy. Final report from the research project MNiSzW, No. N N513 419334. Szczecin 2011. 